\title{
Evaluation of Early Pregnancy Failure with Ultrasound
}

\section{Janet M Burlingame}

Assistant Professor, Department of Obstetrics and Gynecology, and Women's Health, John A Burns School of Medicine University of Hawaii, Honolulu, Hawaii, USA

Correspondance: Janet M Burlingame, MD

1319 Punahou St., Suite 824, Honolulu, HI. 92826, USA

Phone: 808-203-6500, e-mail: burlinga@hawaii.edu

\begin{abstract}
Ultrasound has developed into a powerful tool in the management of early pregnancy failure. However, there is no single finding or measurement that should be used in making a final diagnosis of early pregnancy failure. Instead a combination of clinical, hormonal and ultrasound findings should be used when deciding on the clinical management course.
\end{abstract}

Key words: Ultrasound, first trimester, pregnancy failure, review.

\section{Learning objectives}

- To review the measurements used for dating pregnancies in the first trimester.

- To review the ultrasound criteria used to identify the location of an early pregnancy.

- To review the findings associated with early pregnancy failure.

- To review the importance of a multifactorial approach in the diagnosis of early pregnancy failure and the benefit or serial examinations in the presence of borderline findings.

\section{INTRODUCTION}

Who knew that from the technology of World War II would arise obstetric sonography. ${ }^{1,2}$ Ultrasound technology has progressed so rapidly in the last 50 years, and now with transvaginal sonography (TVS), it is possible to visualize an embryo when it is in the size of a grain of rice. With the advent of TVS, the first report of an early intrauterine gestation was in Vienna in 1967. ${ }^{3}$ This earlier detection has positive implications for earlier detection of pregnancy failure and earlier intervention in ectopic pregnancies. Ultrasound has become the standard by which clinicians diagnose and monitor embryonic age and well-being. This includes ultrasound's utility in evaluation of pregnancy dating, pregnancy failure, ectopic pregnancy, fetal cardiac malformation and chromosomal abnormalities.

\section{DATING}

Key to the diagnosis of pregnancy location and early pregnancy failure is the determination of gestational age. Dating by first trimester ultrasound is accurate and also provides useful information in assessing for growth disorders and in planning scheduled delivery times. Multiple measurements have been used including mean gestational sac diameter (MSD), crownrump length (CRL), and yolk sac diameter. Prior to the identification of a embryo's CRL, it is the MSD that is the most accurate assessment of gestational age. ${ }^{4}$ The formula: "menstrual age in days $=\mathrm{MSD}+30$ " can be used to approximate gestational age. ${ }^{5}$

Once an embryo is identified, the most accurate and preferred measurement of pregnancy age is the embryonic size $(\mathrm{mm})$ or CRL at less than 12.5 weeks (Fig. 1). ${ }^{6-13}$ The formula, developed by Goldstein in 1994, "Gestational age (days) = early embryonic size $(\mathrm{mm})+42$ with a correlation coefficient $r=0.87 ; 95 \%$ confidence limit $=+/-3$ days," can also be used to approximate gestational age. ${ }^{10}$ The CRL can easily be measured transvaginally or transabdominally.

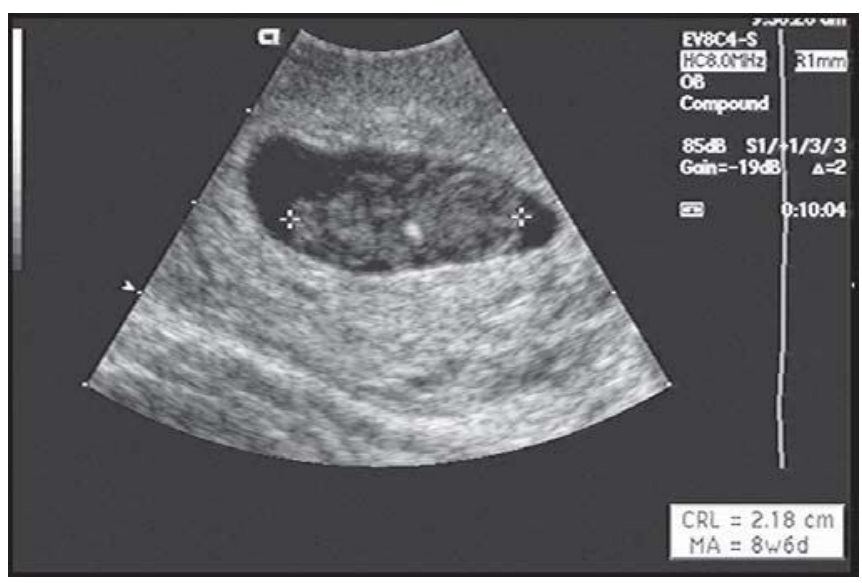

Fig. 1: Crown-rump length $(\mathrm{CRL})$ 


\section{LOCATION OF PREGNANCY}

Multiple measurements and associated findings have also been used to try and determine whether or not an early pregnancy is intrauterine. These would include: the intradecidual sign, the double decidual reaction, and the yolk sac. Perhaps, the earliest sign to be able to distinguish an intrauterine pregnancy (IUP) is the "intradecidual sign" described by Yeh in $1986 .{ }^{14}$ This sign is described as a single rimmed echogenic sac located within a thickened decidua off midline within the uterine cavity. The "intradecidual sign" can be seen by transabdominal sonography (TAS) as early as 3.5 weeks gestation (or 1.5 weeks postconception). Unfortunately, this sign was not reliable when tested with transvaginal sonography and should not be used to differentiate an early IUP from and ectopic pregnancy. ${ }^{15}$ When TVS is used to locate a pregnancy, one would expect to be able to see and IUP with a hCG level of $2000 \mathrm{mIU} / \mathrm{ml} \mathrm{IRP.}{ }^{16,17}$ Other authors recommend using a higher hCG discriminatory level such as 3000 to $4500 \mathrm{mIU} / \mathrm{ml}$ which will decrease sensitivity but increase specificity so may not be of much clinical utility. ${ }^{18,19}$

The double decidual sign (DDS) was historically one of the first reliable transabdominal and transvaginal sonographic findings used to distinguish an IUP from the pseudosac of an extrauterine or ectopic pregnancy. It was described by Bradley in 1982 as "two concentric echogenic rims" around fluid within the endometrial cavity (Fig. 2). It is send as early as 4.5 weeks gestational age (or 2.5 weeks postconception) by transvaginal sonography. ${ }^{20}$ With the advent of transvaginal sonography and thereby earlier detection of the yolk sac, the double decidual sign has become less useful.

The secondary embryonic yolk sac (YS) can be visualized by transvaginal sonography (Fig. 3) at 37 to 40 days and hCG of $2200 \mathrm{mIU} / \mathrm{ml}$, IRP. ${ }^{16}$ When a yolk sac is identified, there is $100 \%$ positive predictive value of an IUP. ${ }^{21}$ However, because a yolk sac may not be present all the time prior to when a normal embryo is identified, YS identification alone is not a reliable single indicator of pregnancy viability. ${ }^{22,23}$ The size of a yolk sac has also been associated with pregnancy outcome. There is a $60 \%$ positive predictive value of abnormal pregnancy outcome when the YS is greater than 2 standard deviations above the mean sac diameter. ${ }^{24,25}$ However, a large YS is, in general, considered a nonspecific finding with early pregnancy failure. $^{25}$

\section{DIAGNOSING PREGNANCY FAILURE}

Once a pregnancy is established as intrauterine, the next clinical question to be asked is regarding the pregnancy's viability. Pregnancy failure has been determined with sonography using multiple measurements including the mean gestational sac diameter, embryonic pole, and embryonic heart pulsations. The sonographic diagnostic cut-offs for pregnancy failure vary depending the degree specificity, sensitivity and the different

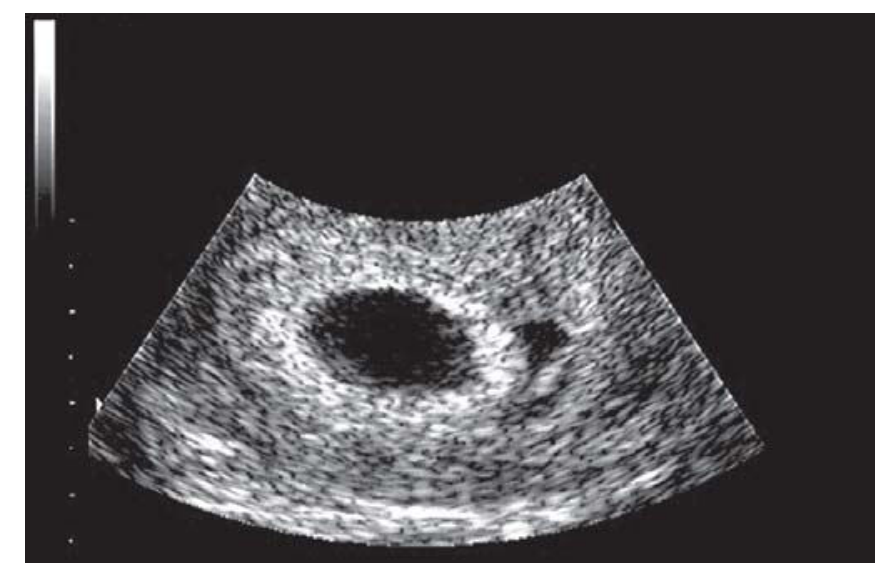

Fig. 2: Double decidual sign (DDS)

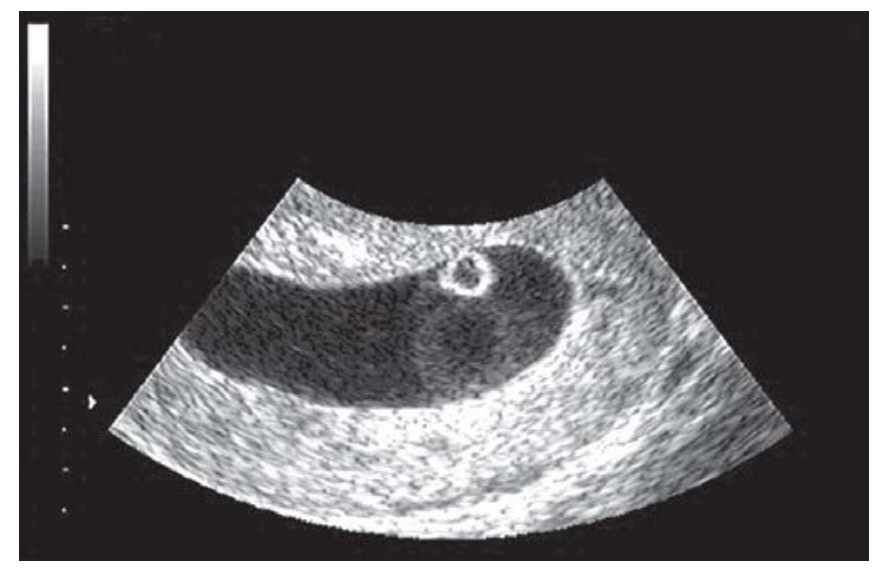

Fig. 3: Yolk sac

author's findings; however, the more common guidelines are summarized in Table 1. ${ }^{14,16,26-28}$

The gestational sac can first be observed by TVS when the sac diameter is $5 \mathrm{~mm}$ at approximately 5 weeks gestation (or 3 weeks postconception). Between the fifth and sixth weeks of pregnancy, the MSD increases by approximately $11 \mathrm{~mm} /$ day. ${ }^{29}$ A small gestational sac as defined in relation to the CRL has been used as a predictor of pregnancy failure. ${ }^{30-32}$ In other series, a large gestational sac in the absence of a yolk sac and/ or embryo is associated with pregnancy failure. When a yolk sac is not identified by a certain MSD, there is an increase risk of pregnancy failure. Various MSDs have been used to predict pregnancy failure when the yolk sac is absent. It has been suggested that anywhere from 13 to $25 \mathrm{~mm}$ for MSD is a good cut-off. ${ }^{33,34}$ If you set the cut-off for MSD high enough, however, there is a $100 \%$ specificity for abnormal pregnancy outcome. This was demonstrated by Nyberg in 1986. Nyberg proposed using major and minor indicators of pregnancy failure to come up with a $100 \%$ positive predictive value. Major criteria were defined as: (i) large size with a MSD > $25 \mathrm{~mm}$ without an 
Janet M Burlingame

Table 1: Guidelines for ultrasound measurements in the first trimester ${ }^{14,16,26-28}$

\begin{tabular}{|c|c|c|c|c|}
\hline \multirow{2}{*}{$\begin{array}{l}\text { Documentation of IUP and } \\
\text { pregnancy failure }\end{array}$} & \multicolumn{2}{|c|}{ Detection } & \multicolumn{2}{|c|}{ Discriminatory } \\
\hline & Transabdominal & Transvaginal & Transabdominal & Transvaginal \\
\hline Intradecidual sign & 3.5 weeks & Poor indicator & & \\
\hline Double decidual reaction & 4-9 weeks & 2-9 weeks & & MSD $10 \mathrm{~mm}$ \\
\hline Gestational sac & & $\begin{array}{l}5 \mathrm{~mm} / 4.5 \text { weeks } \\
\text { MSD } 10 \mathrm{~mm}\end{array}$ & & $\mathrm{hCG}>2000 \mathrm{mIU} / \mathrm{ml}$, IRP \\
\hline Yolk sac & MSD $10 \mathrm{~mm}$ & $\begin{array}{l}37-40 \text { days, } \\
\text { MSD } 6.7 \mathrm{~mm} \text {, } \\
\text { hCG } 2200 \mathrm{mIU} / \mathrm{ml} \text {, } \\
\text { IRP }\end{array}$ & $\begin{array}{l}\text { Poor indicator } \\
\text { MSD } 20 \mathrm{~mm}\end{array}$ & $\begin{array}{l}\text { Poor indicator } \\
\text { MSD } 13 \mathrm{~mm}\end{array}$ \\
\hline Embryo & & & MSD $25 \mathrm{~mm}$ & MSD $18-20 \mathrm{~mm}$ \\
\hline Cardiac activity & & $\begin{array}{l}6 \text { weeks MSD } 16 \mathrm{~mm} \\
\text { fetal pole } 3 \mathrm{~mm}\end{array}$ & Fetal pole $>9 \mathrm{~mm}$ & Fetal pole $>5 \mathrm{~mm}$ \\
\hline
\end{tabular}

embryo or a MSD $>20 \mathrm{~mm}$ without a yolk sac and (ii) distorted gestational sac shape. Minor criteria were defined as: (i) thin decidual reaction $(<2 \mathrm{~mm})$; (ii) week decidual amplitude; (iii) irregular contour; (iv) absent DDS and; (v) low position within the uterus. If one major criteria or three minor criteria were present, there was a $100 \%$ predictive value for abnormal pregnancy outcome. ${ }^{23}$ With the large degree of variability in MSD cut-offs, MSD is not a good single predictor of pregnancy viability, and instead MSD should usually be used in combination with other findings or in serial ultrasound examinations..$^{23,35,36}$

The documentation of an embryo and its appropriate interval growth with development of a heart pulsation is a positive predictor of pregnancy success. In fact, once an embryonic heart rate is documented by sonography, the miscarriage rate decreases to as low as $10 \%{ }^{23,37,38}$ The embryonic heart rate can first be seen by TVS at 36 to 40 days gestation (menstrual age) when the heart tube is just forming (Fig. 4). ${ }^{39,40}$ It is expected that an embryonic heart rate may be documented by the time when the CRL is at greater than 4 to $5 \mathrm{~mm} .^{25,41}$ The embryonic heart rate also has some predictive value in determining pregnancy outcome. The embryonic heart rate at first appearance may be slow but may increase progressively until 9 weeks gestation and then decrease until the end of the first trimester. ${ }^{42,43}$ A slow HR between 6 to 8 weeks gestation has been associated with up to a $25 \%$ poor pregnancy outcome. ${ }^{42,44}$ Although, an embryonic heart rate is not diagnostic of an impending fetal demise, it should warrant a follow-up study.

It is also important to remember that less than expected growth or gestational sac size or low embryonic heart rate may not be associated with pregnancy failure but instead with aneuploidy. Gestational sac morphology, embryonic heart rate and yolk sac morphology all have some value in predicting

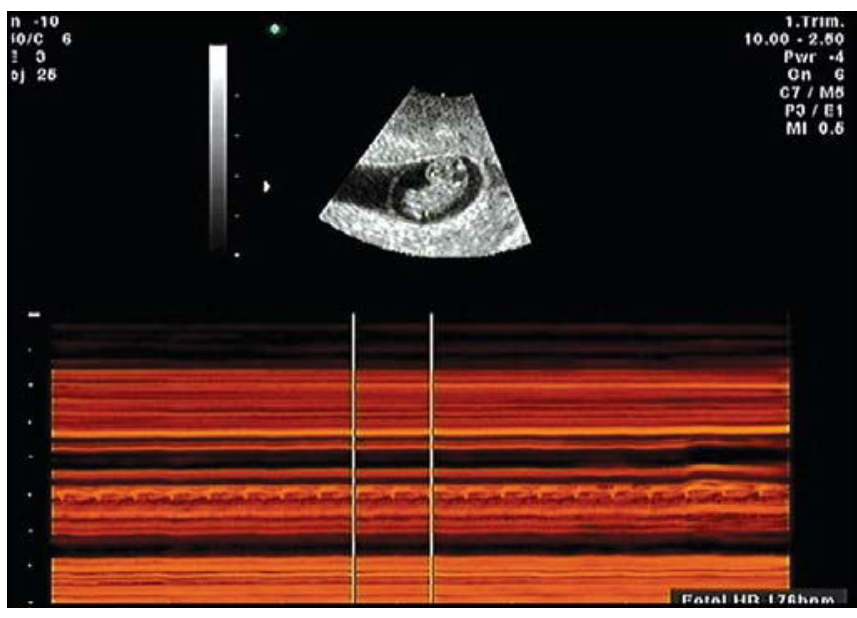

Fig. 4: Embryonic heart rate measured in M-mode

chromosomal abnormalities. ${ }^{23,45,46}$ There is, however, contradictory evidence regarding the predictive value of these findings and caution should be used in counseling the patient about genetic testing. ${ }^{25,47}$ Given the ability to manage most miscarriages without any medical intervention, it is usually safe for the patient to wait for repeat studies while the certainty of the diagnosis is being made. ${ }^{48,49}$

\section{FIRST TRIMESTER DOPPLER: THE CORPUS LUTEUM AND PREGNANCY FAILURE}

More investigational measurements including Doppler and corpus luteum morphology have also been studied as predictors of early pregnancy failure. Doppler has also been used to evaluate the health of the early pregnancy in part by evaluating the early decidual circulation. There is evidence that premature higher resistance maternal circulation within the placenta is 
associated with early pregnancy failure. This has been thought to reflect abnormal invasion of the spiral arterioles with decreased cytotrophoblast invasion; and hence, the creation of inadequate low resistance circulation. ${ }^{50-52}$ It has been hypothesized that the higher resistance maternal like flow promotes oxidative stress and then further damage to the embryo which may contribute to pregnancy failure. ${ }^{27}$ The abnormal placental resistance patterns documented by Doppler and associated with early pregnancy failure are not clinically useful in diagnosing miscarriage. However, the use of Doppler in the late first trimester may become a more useful tool in predicting other developing placental diseases like pre-eclampsia and molar pregnancies. ${ }^{50,53-60}$

Even evaluation of the corpus luteum size and morphology has been investigated to predict early pregnancy failure. Unfortunately, little reliable correlation was found between corpus luteum volume or morphology and hormone (estradiol, progesterone and 17-hydroxyprogesterone) levels. ${ }^{61}$

\section{CONCLUSIONS}

Ultrasound is a strong tool on our diagnostic armamentarium, but no single ultrasound measurement can predict pregnancy failure $100 \%$ of the time. In conclusion, transvaginal sonography is a powerful tool in diagnosing and treating early pregnancy failure. However, it should not be used in isolation especially if the pregnancy is desired. A combination of clinical judgment, hCG, ultrasound findings and repeat ultrasound and/or hormonal studies should be used in the diagnosis and management of early pregnancy failure.

\section{REFERENCES}

1. Nyborg WL. Biological effects of ultrasound: development of safety guidelines. Part I: personal histories. Ultrasound Med Biol 2000;26(6):911-64.

2. Leopold GR. The Radiological Society of North America. Diamond Jubilee lecture. Seeing with sound. Radiology 1990;175(1):23-7.

3. Kratochwil A, Eisenhut L. The earliest detection of fetal heart activity by ultrasound. Geburtshilfe Frauenheilkd 1967;27(2):176-80.

4. Rossavik IK, Torjusen GO, Gibbons WE. Conceptual age and ultrasound measurements of gestational sac and crown-rump length in vitro fertilization pregnancies. Fertil Steril 1988;49(6):1012-7.

5. Nyberg DA, Filly RA, Mahony BS, Monroe S, Laing FC, Jeffrey RB, Jr. Early gestation: correlation of HCG levels and sonographic identification. Am J Roentgenol 1985;144(5):9514.

6. Sladkevicius P, Saltvedt S, Almstrom H, Kublickas M, Grunewald C, Valentin L. Ultrasound dating at 12-14 weeks of gestation. A prospective cross-validation of established dating formulae in in vitro fertilized pregnancies. Ultrasound Obstet Gynecol 2005;26(5):504-11.

7. Taipale P, Hiilesmaa V. Predicting delivery date by ultrasound and last menstrual period in early gestation. Obstet Gynecol 2001;97(2):189-94.

8. Ott WJ. Accurate gestational dating: revisited. Am J Perinatol 1994;11(6):404-8.

9. Lipscomb GH, McCord ML, Stovall TG, Huff G, Portera SG, Ling FW. Predictors of success of methotrexate treatment in women with tubal ectopic pregnancies. N Engl J Med 1999;341(26):1974-8.

10. Goldstein SR, Wolfson R. Endovaginal ultrasonographic measurement of early embryonic size as a means of assessing gestational age. J Ultrasound Med 1994;13(1):27-31.

11. Robinson HP, Fleming JE. A critical evaluation of sonar "crownrump length" measurements. Br J Obstet Gynaecol 1975;82(9):702-10.

12. Schats R, Van Os HC, Jansen CA, Wladimiroff JW. The crownrump length in early human pregnancy: a reappraisal. Br J Obstet Gynaecol 1991;98(5):460-2.

13. Hadlock FP. Sonographic estimation of fetal age and weight. Radiol Clin North Am 1990;28(1):39-50.

14. Yeh HC, Goodman JD, Carr L, Rabinowitz JG. Intradecidual sign: a US criterion of early intrauterine pregnancy. Radiology 1986;161(2):463-7.

15. Laing FC, Brown DL, Price JF, Teeger S, Wong ML. Intradecidual sign: is it effective in diagnosis of an early intrauterine pregnancy? Radiology 1997;204(3):655-60.

16. Bree RL, Edwards M, Bohm-Velez M, Beyler S, Roberts J, Mendelson EB. Transvaginal sonography in the evaluation of normal early pregnancy: correlation with hCG level. Am J Roentgenol 1989;153(1):75-9.

17. Mehta TS, Levine D, Beckwith B. Treatment of ectopic pregnancy: is a human chorionic gonadotropin level of 2,000 $\mathrm{mIU} / \mathrm{ml}$ a reasonable threshold? Radiology 1997;205(2):569-73.

18. Ankum WM, Van der Veen F, Hamerlynck JV, Lammes FB. Transvaginal sonography and human chorionic gonadotrophin measurements in suspected ectopic pregnancy: a detailed analysis of a diagnostic approach. Hum Reprod 1993;8(8):1307-11.

19. Dart R, Kaplan B, Ortiz L, Cloherty J, Lavoie T. Normal intrauterine pregnancy is unlikely in emergency department patients with either menstrual days $>38$ days or beta-hCG $>$ $3,000 \mathrm{mIU} / \mathrm{ml}$, but without a gestational sac on ultrasonography. Acad Emerg Med 1997;4(10):967-71.

20. Bradley WG, Fiske CE, Filly RA. The double sac sign of early intrauterine pregnancy: use in exclusion of ectopic pregnancy. Radiology 1982;143(1):223-6.

21. Nyberg DA, Mack LA, Harvey D, Wang K. Value of the yolk sac in evaluating early pregnancies. J Ultrasound Med 1988;7(3):129-35.

22. Kurtz AB, Needleman L, Pennell RG, Baltarowich O, Vilaro M, Goldberg BB. Can detection of the yolk sac in the first trimester be used to predict the outcome of pregnancy? A prospective sonographic study. AJR Am J Roentgenol 1992;158(4):843-7. 
23. Nyberg DA, Laing FC, Filly RA. Threatened abortion: sonographic distinction of normal and abnormal gestation sacs. Radiology 1986;158(2):397-400.

24. Lindsay DJ, Lovett IS, Lyons EA, et al. Yolk sac diameter and shape at endovaginal US: predictors of pregnancy outcome in the first trimester. Radiology 1992;183(1):115-8.

25. Goldstein SR, Kerenyi T, Scher J, Papp C. Correlation between karyotype and ultrasound findings in patients with failed early pregnancy. Ultrasound Obstet Gynecol 1996;8(5):314-7.

26. Morin L, Van den Hof MC. SOGC clinical practice guidelines. Ultrasound evaluation of first trimester pregnancy complications. Number 161, June 2005. Int J Gynaecol Obstet 2006;93(1):7781.

27. Jauniaux E, Johns J, Burton GJ. The role of ultrasound imaging in diagnosing and investigating early pregnancy failure. Ultrasound Obstet Gynecol 2005;25(6):613-24.

28. Lazarus E. What's new in first trimester ultrasound. Radiol Clin North Am 2003;41(4):663-79.

29. Nyberg DA, Mack LA, Laing FC, Patten RM. Distinguishing normal from abnormal gestational sac growth in early pregnancy. J Ultrasound Med 1987;6(1):23-7.

30. Dickey RP, Gasser R, Olar TT, et al. Relationship of initial chorionic sac diameter to abortion and abortus karyotype based on new growth curves for the 16th to 49th post-ovulation day. Hum Reprod 1994;9(3):559-65.

31. Bromley B, Harlow BL, Laboda LA, Benacerraf BR. Small sac size in the first trimester: a predictor of poor fetal outcome. Radiology 1991;178(2):375-7.

32. Giacomello F. Small sac size as a predictor of poor fetal outcome. Radiology 1992;184(2):578.

33. Hurwitz SR. Yolk sac sign: sonographic appearance of the fetal yolk sac in missed abortion. J Ultrasound Med 1986;5(8):4358.

34. Tongsong T, Wanapirak C, Srisomboon J, Sirichotiyakul S, Polsrisuthikul T, Pongsatha S. Transvaginal sonography in threatened abortions with empty gestational sacs. Int J Gynaecol Obstet 1994;46(3):297-301.

35. Nyberg DA, Filly RA. Predicting pregnancy failure in 'empty' gestational sacs. Ultrasound Obstet Gynecol 2003;21(1):9-12.

36. Rowling SE, Coleman BG, Langer JE, Arger PH, Nisenbaum HL, Horii SC. First-trimester US parameters of failed pregnancy. Radiology 1997;203(1):211-7.

37. Deaton JL, Honore GM, Huffman CS, Bauguess P. Early transvaginal sonography following an accurately dated pregnancy: the importance of finding a yolk sac or fetal heart motion. Hum Reprod 1997;12(12):2820-3.

38. Jouppila P. Clinical and ultrasonic aspects in the diagnosis and follow-up of patients with early pregnancy failure. Acta Obstet Gynecol Scand 1980;59(5):405-9.

39. Tezuka N, Sato S, Kanasugi H, Hiroi M. Embryonic heart rates: development in early first trimester and clinical evaluation. Gynecol Obstet Invest 1991;32(4):210-2.

40. Howe RS, Isaacson KJ, Albert JL, Coutifaris CB. Embryonic heart rate in human pregnancy. J Ultrasound Med 1991;10(7):367-71.
41. Levi CS, Lyons EA, Zheng XH, Lindsay DJ, Holt SC. Endovaginal US: demonstration of cardiac activity in embryos of less than $5.0 \mathrm{~mm}$ in crown-rump length. Radiology 1990;176(1):71-4.

42. Stefos TI, Lolis DE, Sotiriadis AJ, Ziakas GV. Embryonic heart rate in early pregnancy. J Clin Ultrasound 1998;26(1):33-6.

43. Doubilet PM, Benson CB, Chow JS. Long-term prognosis of pregnancies complicated by slow embryonic heart rates in the early first trimester. J Ultrasound Med 1999;18(8):537-41.

44. Doubilet PM, Benson CB. Outcome of first-trimester pregnancies with slow embryonic heart rate at 6-7 weeks gestation and normal heart rate by 8 weeks at US. Radiology 2005;236(2):643-6.

45. Szabo J, Gellen J, Szemere G, Farago M. Significance of hyperechogenic yolk sac in first-trimester screening for chromosome aneuploidy. Orv Hetil 1996;137(42):2313-5.

46. Ferrazzi E, Brambati B, Lanzani A, et al. The yolk sac in early pregnancy failure. Am J Obstet Gynecol 1988;158(1):137-42.

47. Schmidt-Sarosi C, Schwartz LB, Lublin J, Kaplan-Grazi D, Sarosi P, Perle MA. Chromosomal analysis of early fetal losses in relation to transvaginal ultrasonographic detection of fetal heart motion after infertility. Fertil Steril 1998;69(2):274-7.

48. Luise C, Jermy K, Collons WP, Bourne TH. Expectant management of incomplete, spontaneous first-trimester miscarriage: outcome according to initial ultrasound criteria and value of follow-up visits. Ultrasound Obstet Gynecol 2002;19(6):580-2.

49. Sairam S, Khare M, Michailidis G, Thilaganathan B. The role of ultrasound in the expectant management of early pregnancy loss. Ultrasound Obstet Gynecol 2001;17(6):506-9.

50. Papageorghiou AT, Yu CK, Nicolaides KH. The role of uterine artery Doppler in predicting adverse pregnancy outcome. Best Pract Res Clin Obstet Gynaecol 2004;18(3):383-96.

51. Lin SK, Ho ES, Lo FC, Peng SL, Lee YH. Assessment of trophoblastic flow in abnormal first trimester intrauterine pregnancy. Zhonghua Yi Xue Za Zhi (Taipei) 1997;59(1):1-6.

52. Jaffe R, Dorgan A, Abramowicz JS. Color Doppler imaging of the uteroplacental circulation in the first trimester: value in predicting pregnancy failure or complication. Am J Roentgenol 1995;164(5):1255-8.

53. Campbell S. First-trimester screening for pre-eclampsia. Ultrasound Obstet Gynecol 2005;26(5):487-9.

54. Carbillon L, Challier JC, Alouini S, Uzan M, Uzan S. Uteroplacental circulation development: Doppler assessment and clinical importance. Placenta 2001;22(10):795-9.

55. Gomez O, Martinez JM, Figueras F, et al. Uterine artery Doppler at 11-14 weeks of gestation to screen for hypertensive disorders and associated complications in an unselected population. Ultrasound Obstet Gynecol 2005;26(5):490-4.

56. Harrington K, Carpenter RG, Goldfrad C, Campbell S. Transvaginal Doppler ultrasound of the uteroplacental circulation in the early prediction of pre-eclampsia and intrauterine growth retardation. Br J Obstet Gynaecol 1997;104(6):674-81.

57. Harrington K, Goldfrad C, Carpenter RG, Campbell S. Transvaginal uterine and umbilical artery Doppler examination 
of 12-16 weeks and the subsequent development of pre-eclampsia and intrauterine growth retardation. Ultrasound Obstet Gynecol 1997;9(2):94-100.

58. Jaffe R. Development of early uteroplacental circulation. Early Pregnancy 2001;5(1):34-5.

59. Joern H, Funk A, Rath W. Doppler sonographic findings for hypertension in pregnancy and HELLP syndrome. J Perinat Med 1999;27(5):388-94.
60. Prefumo F, Guven M, Ganapathy R, Thilaganathan B. The longitudinal variation in uterine artery blood flow pattern in relation to birth weight. Obstet Gynecol 2004;103(4):764-8.

61. Glock JL, Blackman JA, Badger GJ, Brumsted JR. Prognostic significance of morphologic changes of the corpus luteum by transvaginal sonography in early pregnancy monitoring. Obstet Gynecol 1995;85(1):37-41. 